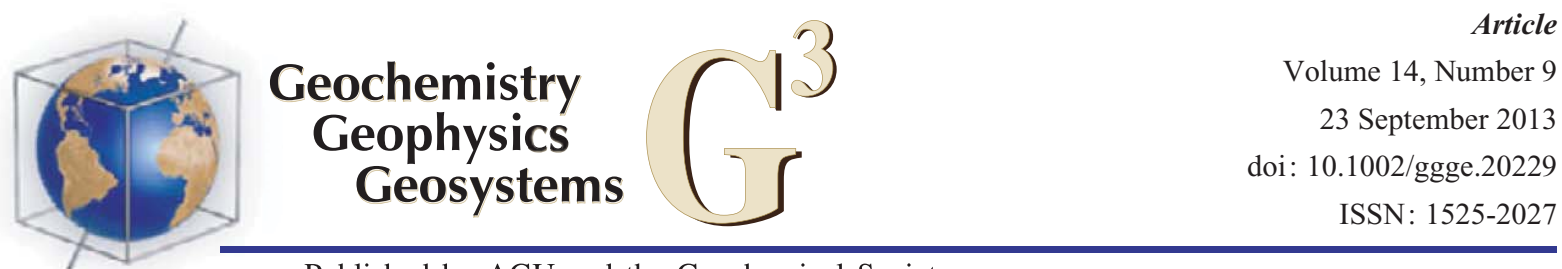

Published by AGU and the Geochemical Society

\title{
Iron-rich nanoparticles formed by aeolian abrasion of desert dune sand
}

\author{
Matthew Baddock, Lucija Boskovic, Craig Strong, and Grant McTainsh \\ Atmospheric Environment Research Centre, Griffith School of Environment, Griffith University, Brisbane, \\ Queensland 4111, Australia (m.baddock@griffith.edu.au)
}

Joanna Bullard

Department of Geography, Loughborough University, Leicestershire, UK

\author{
Igor Agranovski and Roger Cropp \\ Atmospheric Environment Research Centre, Griffith School of Environment, Griffith University, Brisbane, \\ Queensland 4111, Australia
}

[1] Iron-rich nanoparticles in aeolian mineral dust are of considerable importance to biogeochemical cycles. A major determinant of the chemical characteristics of nanoparticles is the parent sediment they are sourced from. The abrasion of dune sand has previously been shown to produce coarse dust $(>1 \mu \mathrm{m})$ during the occurrence of aeolian saltation. In this study, Australian red dune sands were laboratory abraded and emission of particles 18-414 $\mathrm{nm}$ was observed throughout the experiment duration $(\sim 1 \mathrm{~h})$. The mean size of particles was $130 \mathrm{~nm}$ at the start of the test, but this gradually decreased to $110 \mathrm{~nm}$ at the end. The number concentration of particles approximately trebled over the course of the experiment with results suggesting that collisions between mobile sand grains led to the production of new nanosized particles over time. Chemical analysis revealed that these nanoparticles were highly abundant in iron, with some aluminium present. This chemical composition suggests that nanoparticles are produced from the clay coatings surrounding the parent sand grains. The study shows that abrasion from saltation occurring in Australian dune sands can release iron-rich nanoparticles, making them available for downwind transport during blowing dust events.

Components: 5,817 words, 4 figures.

Keywords: dust; iron; abrasion; sand dunes; ultrafines.

Index Terms: 0305 Aerosols and particles: Atmospheric Composition and Structure; 0345 Pollution: urban and regional: Atmospheric Composition and Structure; 4801 Aerosols: Oceanography: Biological and Chemical; 4906 Aerosols: Paleoceanography; 3322 Land/atmosphere interactions: Atmospheric Processes; 1218 Mass balance: Geodesy and Gravity; 1824 Geomorphology: general: Hydrology; 1825 Geomorphology: fluvial: Hydrology; 1826 Geomorphology: hillslope: Hydrology; 1843 Land/atmosphere interactions: Hydrology; 1886 Weathering: Hydrology; 4301 Atmospheric: Natural Hazards; 1625 Geomorphology and weathering: Global Change; 1631 Land/atmosphere interactions: Global Change; 0790 Weathering: Cryosphere.

Received 22 April 2013; Revised 5 July 2013; Accepted 19 July 2013; Published 23 September 2013.

Baddock, M., L. Boskovic, C. Strong, G. McTainsh, J. Bullard, I. Agranovski, and R. Cropp (2013), Iron-rich nanoparticles formed by aeolian abrasion of desert dune sand, Geochem. Geophys. Geosyst., 14, 3720-3729, doi:10.1002/ggge.20229. 


\section{Introduction}

[2] Measuring the characteristics of mineral nanoparticles in order to help understand the complex role these particles play in environmental systems is an emerging area in geosciences [Hochella et al., 2008]. The effect of nanoscale particles in biogeochemical cycles is of considerable interest because these particles do not necessarily behave in the same way as coarser particles $(>1 \mu \mathrm{m})$ [Buzea et al., 2007; Hochella et al., 2008; Raiswell and Canfield, 2012]. Dust storms are a major source of mineral nanoparticles in the atmosphere, with such fine particles known to be numerous in the suspended sediment of raised dust [e.g., d'Almeida and Schütz, 1983; Shi et al., 2005; Kandler et al., 2009].

[3] A primary control on the chemical properties of suspended dust is its parent sediment. The deposition of dust rich in iron is a key input of $\mathrm{Fe}$ to iron-limited open ocean regions [Jickells et al., 2005; Mahowald et al., 2009; Raiswell and Canfield, 2012]. Iron fertilization experiments in the ocean have shown that bioavailable Fe supply is a principal control on the dynamics of phytoplankton blooms in high nutrient low chloropyll areas, such as the Southern Ocean [Boyd et al., 2007]. Phytoplankton productivity in turn influences the biogeochemical cycle of carbon, including the drawdown of $\mathrm{CO}_{2}$ from the atmosphere, which affects the Earth's climate [Jickells et al., 2005; Shao et al., 2011]. Marine primary productivity can also affect radiative forcing through the formation of atmospheric aerosols by oxidation of dimethylsulfide when it becomes ventilated after production by the upper ocean ecosystem [Gondwe et al., 2003; Cropp et al., 2005]. The relationship between iron input and phytoplankton response is recognized as a highly significant linkage between major environmental systems. While the entire fraction of dust deposited into the ocean contributes to the overall input of $\mathrm{Fe}$, iron-rich nanoparticles in dust transport have the potential to play a particularly significant role in promoting marine productivity and therefore influencing biogeochemical cycles because of their large surface area [Usher et al., 2003; Shi et al., 2012]. For example, rainedout nanoparticles with a large surface area have a higher dissolution rate than more crystalline (larger) $\mathrm{Fe}$ oxide minerals and thereby have potentially increased bioavailaibility [Raiswell and Canfield, 2012; Shi et al., 2012].
[4] Dust in the atmosphere also has a direct radiative influence, with the scattering and absorption effect of the aerosol being strongly determined by its particle size, shape, and iron content characteristics [Sokolik and Toon, 1999; Alfaro et al., 2004; Gassó et al., 2010]. The contribution to such forcing by nanoscale particles, especially those that are iron rich, is uncertain, with these particles also potentially significant in atmospheric photochemical reactions [Usher et al., 2003]. At the Earth's surface, there are also believed to be implications for iron-bearing nanoscale dust particles in the formation of rock varnish [Dorn et al., 2013].

[5] To increase our understanding of the role that nanoparticles may play in both complex biogeochemical cycling and specific atmospheric and terrestrial processes, it is essential to understand the origin and formation of submicron particles present in suspended mineral dust. Shi et al. [2009] produced compelling evidence for the formation of iron nanoaggregates via cloud processing, by comparing wet and dry deposited Saharan dust and finding iron nanoaggregates in the rained-out sample only. They also conducted a series of laboratory experiments on synthetic goethite, which provided further evidence that iron-rich nanoparticles could form under the influence of simulated cloud processes.

[6] The present study investigates another nanoparticle formation process, that of aeolian abrasion. Notably, abrasion occurs very early in the dust emission process, when predominantly sand sized grains collide with each other as well as the soil surface during the near-surface wind blown transport process of saltation. The impact of these collisions can result in smaller particles being created by their liberation from larger grains. This is predominantly by the removal of smaller particles attached to the larger grains, the breakup of similar sized particles existing in an aggregated state, or the chipping off of surface coatings around the sand grains [Gillette and Walker, 1977; Gomes et al., 1990; Wright et al., 1998; Bullard et al., 2004]. Laboratory abrasion studies have demonstrated the generation of dust-sized particles $(1-10 \mu \mathrm{m})$ from Australian dune sands. Significantly, the quartz grains of the Simpson Desert have red clay coatings which are iron rich [Folk, 1976; Wasson, 1983] and are highly susceptible to removal by abrasion, forming iron-rich dust-sized particles [Bullard et al., 2004, 2007]. The presence of such iron film coatings on sand grains and smaller particles has in fact long been recognized and continues to be a 
research topic [e.g., Folk, 1976; Walker, 1979; Pell and Chivas, 1995; Scheuvens et al., 2011].

[7] In studying the particle size of mineral aerosols near to source in the Sahara, d'Almeida and Schütz [1983] accounted for suspended particles of $<0.20 \mu \mathrm{m}$ diameter by suggesting a possible role for the process of "sandblasting" as described by Gillette and Walker [1977]. Gillette and Walker had earlier identified that the removal of clay coatings present on quartz grain surfaces during saltation was one mechanism that created fine dust-sized particles. While hypothesizing that sandblasting was important, d'Almeida and Schütz [1983] were uncertain of the extent to which abrasion created a nanoscale fraction [Gomes et al., 1990]. The mechanism of aeolian abrasion at the finest sizes of sediment continues to remain poorly understood. Given the postulated significance of iron-rich mineral nanoparticles in biogeochemical cycles, this paper examines aspects of nanoparticle formation from iron-rich dune sands. The aim was to assess the potential for laboratory-based physical generation of suspendible submicron particles from Australian desert sands, and determine the chemical characteristics of resultant nanoscale particles.

\section{Methods}

\subsection{Sand Samples}

[8] A sand sample was taken from the top $0-5 \mathrm{~cm}$ on the crest of a large red, linear sand dune located near Windorah, western Queensland, Australia (E $\left.142^{\circ} 32.930^{\prime}, \mathrm{S} 25^{\circ} 21.850^{\prime}\right)$. The strong red color of this similar sand in red dunefields has been linked with the presence of iron-rich clay coatings around quartz grains [Wasson, 1983; Bullard and White, 2002; Bullard et al., 2004, 2007]. The study sand is from the same sediment sample that Bullard et al. [2004] designated as R35 in their supermicron abrasion tests, and the full descriptive details of the sand is provided in that work. Inspection of the parent sand was carried out before any abrasion at high magnification using a scanning electron microscope (SEM).

\subsection{Details of Laboratory Experiments}

[9] The laboratory-based abrasion experiment followed closely the procedure described by Bullard et al. [2004, 2007]. A $30 \mathrm{~g}$ sample of the study sand was placed at the bottom of a test tube-shape glass abrasion chamber $(40 \mathrm{~cm}$ tall by $10 \mathrm{~cm}$ diameter) and airflow was introduced to agitate the sample. A sample of $30 \mathrm{~g}$ was used because $\mathrm{Bul}$ lard et al. [2004] found that this quantity generated the highest amount of fine material, $1-10 \mu \mathrm{m}$, for four tested masses of sample. The introduced flow was clean compressed air which was passed through two high efficiency particulate air (HEPA) filters arranged in series to remove all extraneous aerosols from the input stream. Preliminary tests of the apparatus showed that an inflow rate of 40 $\mathrm{L} / \mathrm{min}$ was necessary to agitate the sand grains to a maximum bounce height of around $8 \mathrm{~cm}$ from the base of the chamber, the same agitation height used by Bullard et al. [2004].

[10] The suspended particles within the chamber were drawn upward through an outlet pipe where the flow was subsequently sampled isokinetically. The particles were then passed through a Scanning Mobility Particle Sizer (SMPS) system used for measurements of the submicron size distribution and concentration of the test aerosol. The SMPS system consists of an impactor which removes particles above a known particle size by inertial impaction, a charger $(10 \mathrm{~m} \mathrm{Ci} 85 \mathrm{Kr}$, model 3012 , TSI Inc., St. Paul, MN) used to neutralize particles before their entry to the Differential Mobility Analyzer (DMA) (Model 3080, TSI Inc., St. Paul, MN), which is used to separate particles according to their electrical mobility [Hinds, 1999], and a Concentration Particle Counter (CPC) (Model 3010, TSI Inc., St. Paul, MN) used for measurement of particle concentration. The upper cutoff limit to the measured distributions was fixed by the impactor, and at the lower end, the instrument geometry determined by the specified sampling time. This established limits of 414 and $18 \mathrm{~nm}$, respectively.

[11] Each scan duration (including subsequent reset period) was set at 4 min to give the SMPS adequate scanning time to derive an accurate PSD at regular intervals throughout the experiment. The compressed air tanks had the capacity to sustain flow at the required rate for an overall period that enabled 14 four min scans $\left(t_{1}-t_{14}\right)$. At the start of the final scan $\left(t_{14}\right)$ therefore, the sand had undergone agitation constantly for a total of 52 min. Because the determination of each PSD per scan was not instantaneous, but was determined throughout each scan, the time under abrasion is given for the start of a given scan. Thus, time under abrasion is calculated by $4 t_{x}-1$ (where $t_{x}$ is scan run number).

[12] A subsample of the test aerosol particles were collected with a thermophoretic precipitator (TP) 

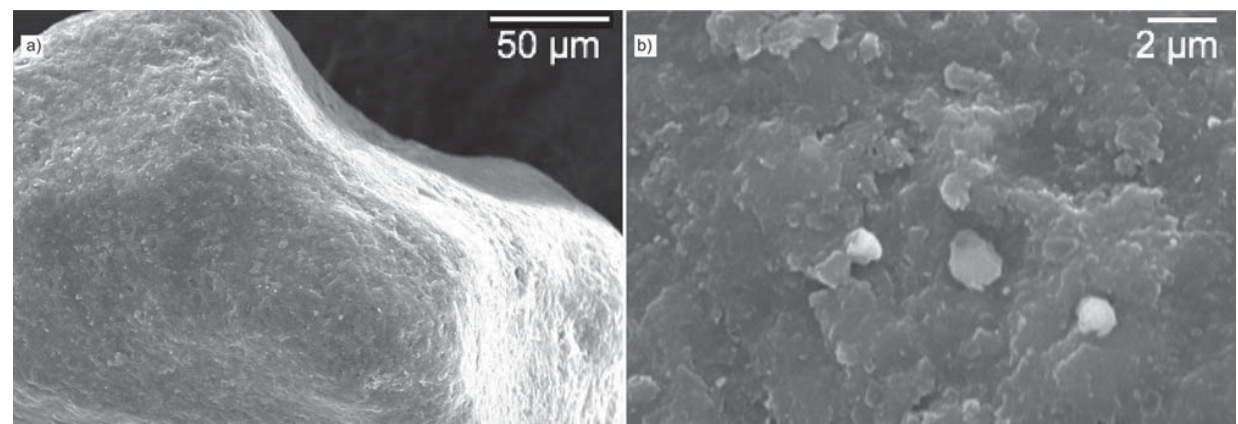

Figure 1. Scanning electron micrographs of a sand grain from the Windorah sample before undergoing laboratory abrasion. (a) Portion of the grain and (b) center of Figure 1a.

[Boskovic and Agranovski, 2012] for analysis by a transmission electron microscope (TEM) equipped with an Energy Dispersive X-ray (EDX) spectrometer (JEOL 2100) to provide high-resolution imaging and analysis of the chemical composition of individual particles [e.g., Shi et al., 2009]. The TP operation principle is based on passage of an aerosol stream through a narrow slot between hot and cold plates. An aerosol particle in that stream experiences a thermophoretic force in the direction of decreasing temperature [Hinds, 1999]. The temperature difference between the plates was kept at $200,000 \mathrm{~K} / \mathrm{m}$ and surface temperatures of the hot and cold plates were measured with K-type thermocouples. For collection of the particles for subsequent analysis by TEM, 200 mesh carboncoated copper grids were used.

\section{Results}

\subsection{Particle Size Distributions}

[13] SEM images show a portion of an individual sand grain and a magnified view of its surface, prior to undergoing the abrasion simulation (Figure 1a). Submicron particles attached to the unabraded grain surface and portions of the surface coating $<1 \mu \mathrm{m}$ are both evident (Figure $1 \mathrm{~b}$ ).

[14] Particle size distributions (PSDs) $<414 \mathrm{~nm}$ maximum diameter are presented at five selected time intervals through the abrasion experiment (Figure 2). While under agitation, the dune sand consistently released particles $<400 \mathrm{~nm}$. The PSDs show that the number concentrations were comparatively low and remained steady for the

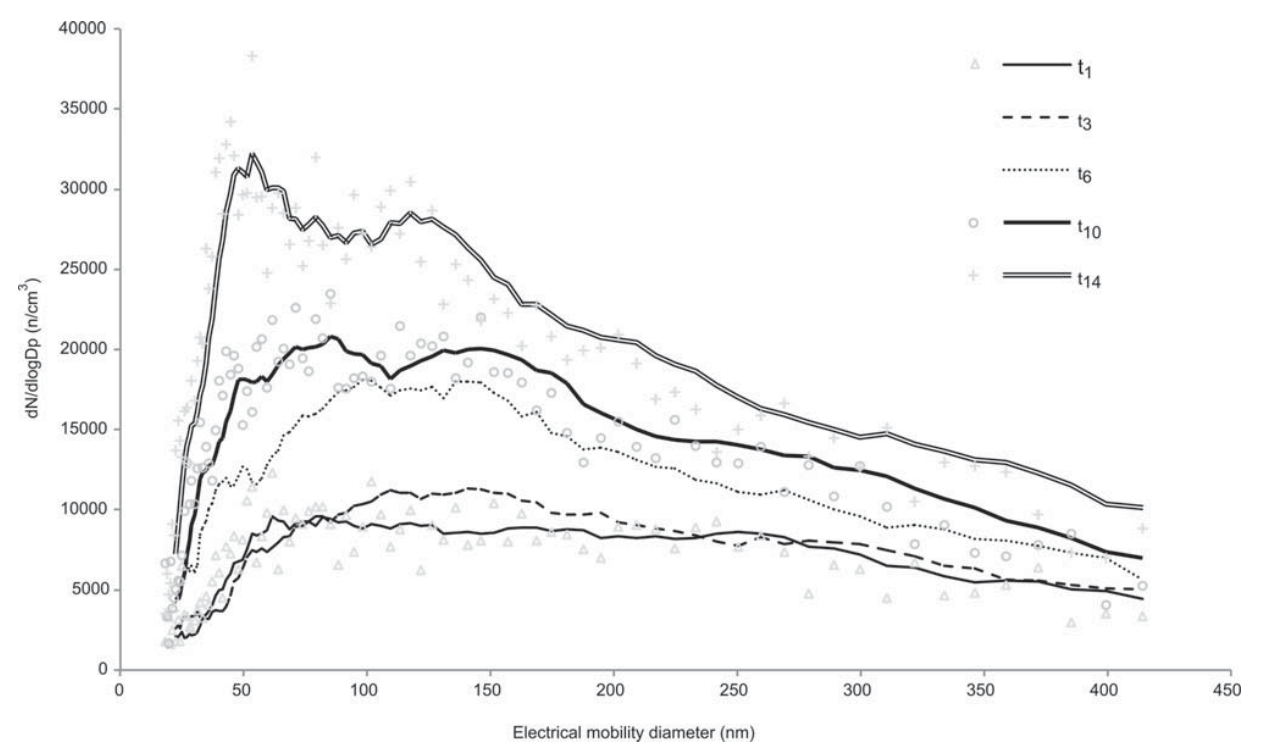

Figure 2. Particle size distributions at five selected scans throughout the abrasion experiment. For ease of interpretation, distributions are smoothed using a seven step running mean with individual points (gray symbols) shown for scan $t_{1}, t_{10}$, and $t_{14}$. Final scan was $t_{14}$. The plots show data for each time interval and are not cumulative. 


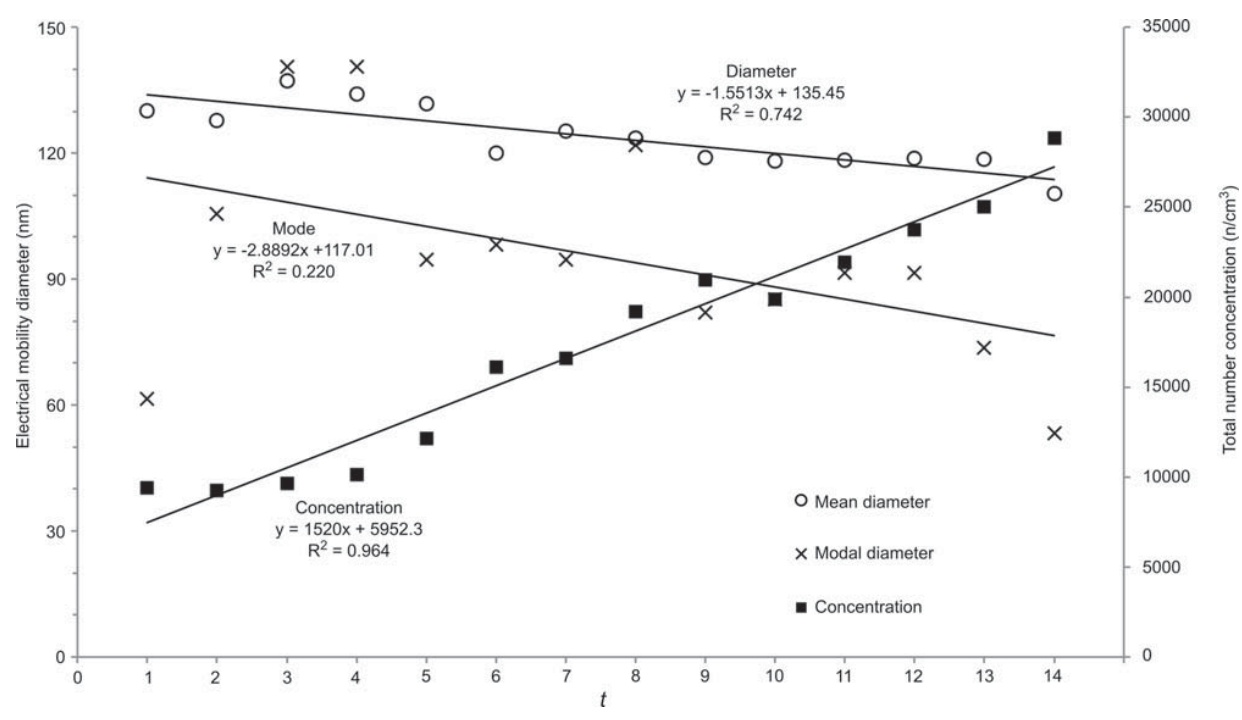

Figure 3. Mean and modal particle diameter and total number concentration for each scan $\left(t_{1}-t_{14}\right)$ throughout the abrasion experiment. Reported mode number is modal value of running mean smoothed data (Figure 2).

early scans of $t_{1}-t_{3}$. By $t_{8}$, however, the total concentration had approximately doubled from the value in $t_{1}$ (Figure 3). During the final scan $\left(t_{14}\right)$, the total concentration was around three times that initially observed in $t_{1}$.

[15] Along with the observed increase in total concentration, there was also a clear change in the form of the PSDs as the time under abrasion increased. From relatively broad peaks in the PSDs across the range 75-200 nm seen for runs $t_{1}-t_{3}$, the peaks became finer in size and narrower in range (more peaked) through time (Figure 2). By $t_{14}$ the peak became a small range around 50 $\mathrm{nm}$. A clear trend is seen for mean particle diameter which decreased from 130 to $110 \mathrm{~nm}$ between the first and last scan (Figure 3). While more erratic given the variability of PSDs, the modal value also exhibited a decreasing trend from $t_{2}$ onward. For the smoothed values of a seven step running mean, $R^{2}$ was 0.22 for the reduction in mode particle diameter through the experiment, which was improved to 0.59 if $t_{1}$ was not considered with its relatively wide PSD peak and indistinct mode (Figure 2).

\subsection{TEM and EDX Analysis}

[16] The TEM imagery demonstrates the morphology of the nanoparticles, and their presence as both individually identifiable particles (e.g., 003) and in clustered forms (002 and 004). A representative example is shown in Figure 4a.
[17] The EDX analysis provided information on the main elements present for a suite of targeted particles (Figures $4 \mathrm{~b}-4 \mathrm{~d}$ ). As well as revealing peaks in $\mathrm{O}$ and $\mathrm{Si}$ that are constituents of quartz grains and clay minerals [Jeong, 2008; Scheuvens et al., 2011], all sample points clearly showed the presence of $\mathrm{Fe}$. Al was also seen to be present in the analyzed spectra, and $\mathrm{Fe}$ and $\mathrm{Al}$ together is known to be indicative of the clay coatings attached to grains of this red sand [Bullard et al., 2004]. For points 002 and 003 , the $\mathrm{Fe}$ signal exceeded that of $\mathrm{Si}$, with the relative proportion of Fe especially high in 003, showing these nanoscale particles to be iron bearing.

\section{Discussion}

\subsection{Nanoparticle Generation by Aeolian Abrasion}

[18] From the micron-scale sand abrasion experiments of Bullard et al. [2004, 2007] it was suggested that the output dust-sized particles could have one of three origins; from the release of resident fines, chipping and spalling from sand grains, or removal of clay coatings from around the grains. All three types of particles were observed from the start of their experiment, however, the output of "resident fines" dominated the early PSDs. At this coarse particle scale, resident fines are governed by gravitational forces and easily 

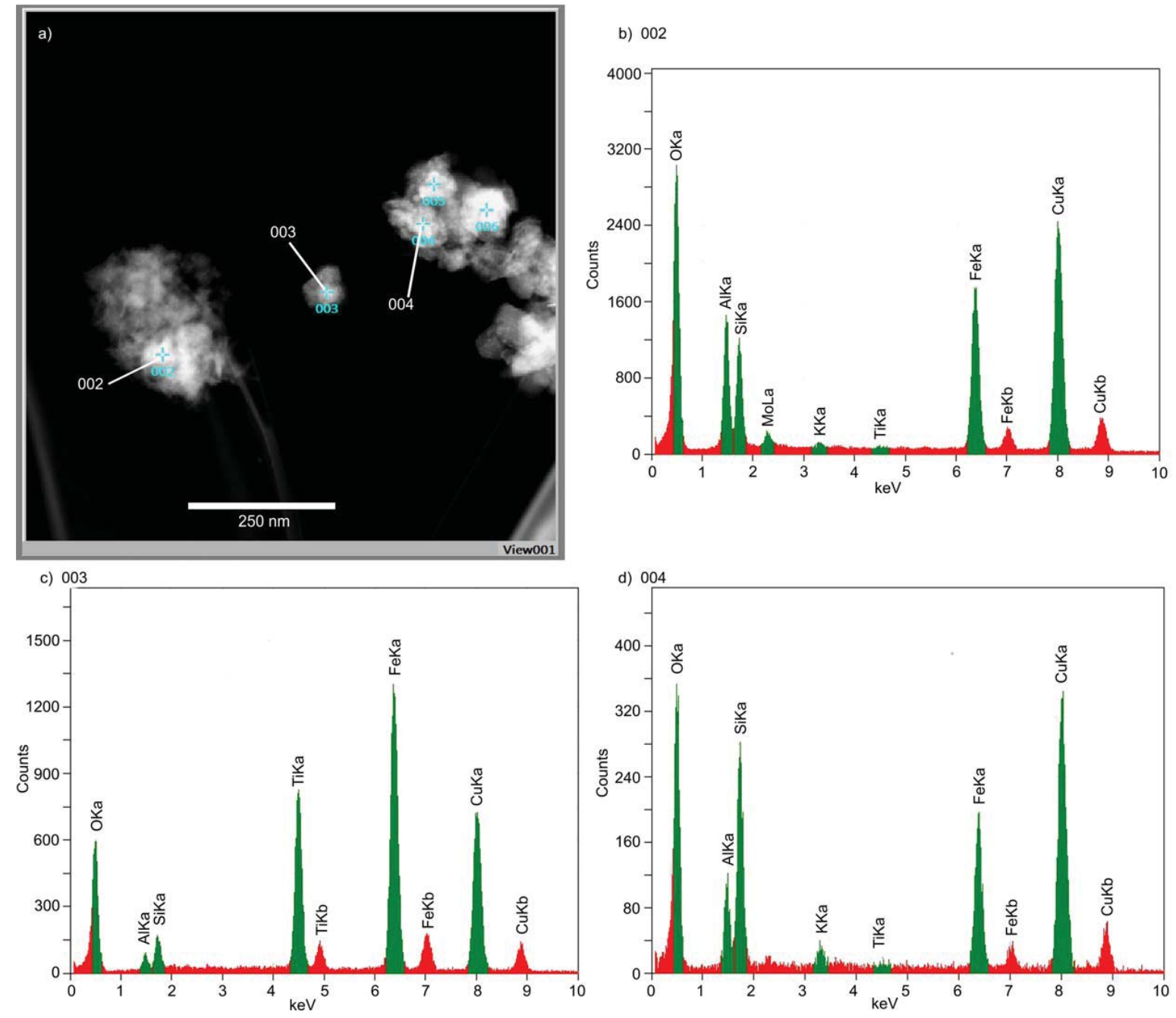

Figure 4. (a) TEM micrograph showing the presence of nanoparticles, including the points where EDX spectra were obtained (shown in b-d). Note different vertical scale across spectra. Cu spike in spectra is from the TEM collection grid.

mobilized by saltation and this fraction accounted for the bulk of the abrasion products by weight. However, this is a finite population and its importance in the PSD decreases through time. With time under abrasion, the PSDs became dominated by particles generated by the removal of compacted clay coatings which produces a dominant mode $<10 \mu \mathrm{m}$ in diameter (typically $2-4 \mu \mathrm{m}$ ). Bullard et al. [2007] found a statistically significant relationship between the mass of dust produced by abrasion of dune sands and the amount of clay coating present.

[19] In the nanoparticle generation experiments presented here, we only focus on particles $<400$ $\mathrm{nm}$ which were not detectable using Bullard et al.'s [2004] methodology. Nanoparticles were detected within the first $4 \mathrm{~min}$ of the experiments
(Figure 2) which suggests they were released under abrasion from the outset of the experiment. It is possible that some individual (i.e., free, nonaggregated) nanoparticles were present in the sample to partly account for this initial output. At the nanoscale, however, cohesive forces rather than gravitational forces are likely to dominate, making individual occurrence less likely because nanoparticles will tend to aggregate. The strength of these cohesive forces, and hence the stability of the aggregates will, however, vary considerably as a result of differences in particle shape, size, geochemistry and surface roughness [Mason et al., 2011; Klose and Shao, 2012]. Some nanoparticles may therefore be only very loosely bonded to each other, or to the surface of larger particles. For example, the SEM analysis revealed the presence 
of nanoscale particles attached to the surface of larger clay skinned sand grains before any abrasion took place (Figure 1b). The collision between mobile sand grains provides a mechanism for the rapid liberation of any loosely bonded particles as the attractive forces between the submicron-sized particles and the larger grains are overcome by the kinetic energy of impacts [Gomes et al., 1990; Kok et al., 2012].

[20] If the release of loosely bonded or resident nanoparticles was the only mechanism operating over time, following Bullard et al.'s [2004] argument, the yield of nanoparticles should decrease as the supply becomes exhausted. The observation that the area under the distribution (and total concentration) of nanoparticles increases with time provides compelling evidence that a second source of nanoparticles is present (Figures 2 and 3). In this case, the suggestion is that a second source is provided by the breakup of nanoparticles existing as aggregates of similar sizes, or, through removal of those nanoparticles more tightly bound to the larger grains, and the gradual release of these as a result of a sustained input of energy [Alfaro, 2008; Kok et al., 2012].

[21] This latter process is concordant with Bullard et al.'s [2004] removal of clay coatings for the same sand sample, as well as work by d'Almeida and Schütz [1983] which offers supporting evidence for this assertion. The latter study suggested that a peak particle size of 100-160 nm measured in airborne Saharan dust was due to particles generated by the sandblasting process described by Gillette and Walker [1977] which includes the removal of clay coatings from quartz grains [also Gomes et al., 1990]. Thus, interactions between colliding sand grains and the removal of outer skins to form new nanosized fragments appears the dominant mechanism behind the increase in nanoparticle concentration over time. As particles become liberated from the clay skins, and the number of particles increases, the clay skin nanoscale fragments will also become involved in collisions. The increased chance of collision due to the larger number of particles will also contribute to a rise in concentration over time.

[22] The other important characteristic of the change in PSDs is the overall decrease in the modal particle size through the duration of the experiment, reflecting an increased presence of finer particles over time (Figures 2 and 3). The emergence of a finer-sized fraction over time offers further evidence for the abrasion process as it con- tinually contributes finer particles that cause a positive skewing of the size distribution. Bullard et al. [2004], in tests of the same sand, showed that with time abrasion preferentially produced material in the finer tail of the $1-10 \mu \mathrm{m}$ distribution.

[23] In the PSDs of suspended dust measured during Saharan conditions, "dust wind" conditions, one significant size peak was reported around $80 \mathrm{~nm}$ [Kandler et al., 2009]. Kandler et al. [2009] attributed this peak to possible background anthropogenic influences, but in reporting a similar sized peak, d'Almeida and Schütz [1983] asserted it was crustderived mineral dust. The evidence from our laboratory experiment is that mineral dust of this size can be emitted by abrasion of natural sediments.

[24] An important consideration is the differences between the natural abrasion mechanism and the laboratory representation of the process used here. The test chamber conditions are likely to exaggerate abrasion, due to added granular impacts with the surrounding glass surfaces. Attempting to sample nanoparticles generated by abrasion in a field setting however would be almost impossible. Given the comparable abrasion simulations of Wright et al. [1998] and Bullard et al. [2004], the simulation of abrasion adopted here is considered to be an adequate trade-off between real physical process and laboratory experimental practicability.

\subsection{Chemical Properties of Nanoparticles}

[25] The suspended nanoparticles trapped on TEM grids and analyzed by EDX (10 samples) were all found to be iron rich. The particle from which the Figure $4 \mathrm{c}$ spectrum was obtained was particularly small $(<50 \mathrm{~nm})$ and demonstrated an Al signal and an especially pronounced $\mathrm{Fe}$ intensity. The presence of Si, Al, and Fe signatures in the composition of all analyzed points provides strong evidence that such particles may represent small pieces of the iron-rich clay coating surface of the sand grains [Bullard et al., 2004; Scheuvens et al., 2011]. The overall compositions are also similar to iron oxide clays found in the case of Asian dust [Jeong, 2008]. The relative Fe prominence in the Figure 4 spectra (and for other EDX points not shown) is especially significant. Ratios of the Fe to Si peaks for these submicron particles are considerably greater than for dust particles $\sim 10 \mu \mathrm{m}$ produced via abrasion of the same Windorah sand [Bullard et al., 2004]. This result suggests that the nanoparticles generated from abrasion of red dune sands are particularly iron abundant, relative to larger dust particles. This enhanced relative Fe 
richness in finer particles is recognized for submicron dust [Shi et al., 2012] including that emitted from central and southern Saharan sources [Kandler et al., 2007; Chou et al., 2008].

[26] Based on a sampling of Australian desert aerosols in transport within the Lake Eyre Basin (LEB), Radhi et al. [2010a, 2010b] found that $\mathrm{Fe} / \mathrm{Si}$ mass ratios for submicron particles were not any higher than for particles $>1 \mu \mathrm{m}$. The aerosols their studies examined however were not sourced exclusively from parent dune sands, as here and by Bullard et al. [2004], therefore this result is to be expected. Radhi et al. [2010a, 2010b] suggested that ultrafine particles in the LEB have mean $\mathrm{Fe} / \mathrm{Si}$ mass ratios $(\sim 0.35)$ that are globally relatively high. They stated that this reflects the high amount of $\mathrm{Fe}$ in Australian desert sediments. While this ratio value is broadly comparable with the elemental composition in Figure $4 \mathrm{~d}$, the other EDX sample points revealed Fe proportions on nanoparticles actually greater than Si (Figures $4 \mathrm{~b}$ and $4 \mathrm{c}$ ) indicating some are extremely iron rich. With the abundance of iron in the clay coatings of red dune sands, the findings of the current process study demonstrate that the abrasion process can lead to the release of iron-rich nanoparticles from dune sands. This process could contribute $\mathrm{Fe}$ abundant nanoscale particles to the iron-rich mineral aerosol loading of Australia.

[27] Further comparison of our results with the comprehensive Radhi et al. [2010a] aerosol study shows interesting but tentative evidence for Australian dunefields acting as sources of iron-rich nanoparticles. Radhi et al. [2010a] examined aerosol samples from two dust transport events with different source areas. They determined that the $\mathrm{Fe} / \mathrm{Si}$ mass ratio for particles $\leq 560 \mathrm{~nm}$ was greater for the event associated with a portion of the Simpson Desert dunefield than the other event not associated with a dune source.

\section{Conclusion}

[28] In this laboratory experimental study, Australian desert dune sands were abraded to examine the emission of nanoscale particles. Particles $<400 \mathrm{~nm}$ were emitted from the sand as soon as agitation began and their total concentration increased during the experiment. Changes in the particle size distributions over time suggest that initially, nanoparticle production is driven by the liberation by kinetic impacts of those nanoparticles loosely bound to the surfaces of the larger grains. As abrasion progressed, the further breakup of nanoparticles existing as aggregates of similar size, or removal of those nanoparticles more tightly bound to the larger grains can occur to sustain their release. The increase in total particle concentration over time increases the chances of particle collision and therefore the further generation of new particles. The decrease in the modal size provided evidence for the generation of relatively finer nanoparticles by abrasion. Analysis by EDX showed these nanoscale particles to be iron rich and were likely pieces of the clay coatings from around the sand grains, which were removed by grain collisions during abrasion. These outer coatings are most susceptible to abrasion, and their chemical composition means that iron-rich nanoparticles are readily produced under abrasion from these dune sands.

[29] In terms of the wider significance, while the emission of nanoparticles abundant in iron was clearly observed, it was beyond the scope of this study to characterize the form or potential bioavailability of the iron. The form of $\mathrm{Fe}$ in dust and its availability to marine ecosystems represent a complicated control on the effect that iron input actually has on such systems. Notwithstanding this, the highly soluble nature of nanoparticles makes them potentially extremely significant as nutrient inputs. The transport and deposition of iron-rich nanoparticles generated from abrasion of dune sands could well therefore be relevant to biogeochemical cycling in those marine regions affected by dust pathways from Australian dune sources. Comparison of this laboratory work with studies of chemical properties from larger scale aerosol transport research indeed suggests that the Australian dunefields are a source of iron in submicron-sized dust. The process observations here provide evidence that aeolian abrasion is capable of contributing nanoscale iron-rich aerosols from Australian dune sands.

\section{Acknowledgment}

[30] The authors are grateful for the comments of two anonymous reviewers which helped to improve the manuscript.

\section{References}

Alfaro, S. C. (2008), Influence of soil texture on the binding energies of fine mineral dust particles potentially released by wind erosion, Geomorphology, 93, 157-167.

Alfaro, S. C., S. Lafon, J. L. Rajot, P. Formenti, A. Gaudichet, and M. Maillé (2004), Iron oxides and light absorption by 
pure desert dust: An experimental study, J. Geophys. Res., 109, D08208, doi:10.1029/2003JD004374.

Boskovic, L., and I. E. Agranovski (2012), A new thermophoretic precipitator for off-line particle analysis, Clean Soil Air Water, 40, 565-570, doi:10.1002/clen.201100173.

Boyd, P. W., et al. (2007), Mesoscale iron enrichment experiments 1993-2005: Synthesis and future directions, Science, 315, 612-617, doi:10.1126/science.1131669.

Bullard, J. E., and K. H. White (2002), Quantifying iron oxide coatings on dune sands using spectrometric measurements: An example from the Simpson-Strzelecki Desert, Australia, $J$. Geophys. Res., 107(B6), 2125, doi:10.1029/2001JB000454.

Bullard, J. E., G. H. McTainsh, and C. Pudmenzky (2004), Aeolian abrasion and modes of fine particle production from natural red dune sands: An experimental study, Sedimentology, 51, 1103-1125, doi:10.1111/j.1365-3091.2004.00662.x.

Bullard, J. E., G. H. McTainsh, and C. Pudmenzky (2007), Factors affecting the nature and rate of dust production from natural dune sands, Sedimentology, 54, 169-182, doi: 10.1111/j.1365-3091.2006.00827.x.

Buzea, C., I. I. Pacheco, and K. Robbie (2007), Nanomaterials and nanoparticles: Sources and toxicity, Biointerphases, 2, MR17-MR71, doi:10.1116/1.2815690.

Chou, C., P. Formenti, M. Maille, P. Ausset, G. Helas, M. Harrison, and S. Osborne (2008), Size distribution, shape, and composition of mineral dust aerosols collected during the African monsoon multidisciplinary analysis special observation period 0: Dust and biomass-burning experiment field campaign in Niger, January 2006, J. Geophys. Res., 113, D00C10, doi:10.1029/2008JD009897.

Cropp, R. C., A. J. Gabric, G. H. McTainsh, and R. A. Braddock (2005), Coupling between ocean biota and atmospheric aerosols: Dust, dimethylsulphide, or artifact?, Global Biogeochem. Cycles, 19, GB4002, doi:10.1029/2004GB002436.

d'Almeida, G. A., and L. Schütz (1983), Number, mass and volume distributions of mineral aerosol and soils of the Sahara, J. Clim. Appl. Meteorol., 22, 233-243.

Dorn, R. I., S. J. Gordon, D. Krinsley, and K. Langworthy (2013), Nanoscale: Mineral weathering boundary, in Treatise on Geomorphology, Weathering and Soils Geomorphology, vol. 4, edited by G. A. Pope and J. Shroder, pp. 44-69, Academic, San Diego, Calif.

Folk, R. L. (1976), Reddening of desert sands: Simpson Desert, N.T., Australia, J. Sediment. Petrol., 46, 604-615.

Gassó, S., V. H. Grassian, and R. L. Miller (2010), Interactions between mineral dust, climate and ocean ecosystems, Elements, 6, 247-252, doi:10.2113/gselements.6.4.247.

Gillette, D. A., and T. R. Walker (1977), Characteristics of airborne particles produced by wind erosion of sandy soil, High Plains of West Texas, Soil Sci., 123, 97-110.

Gomes, L., G. Bergametti, G. Caudé-Gaussen, and P. Rognon (1990), Submicron desert dusts: A sandblasting process, $J$. Geophys. Res., 95, 13,927-13,935.

Gondwe, M., M. Krol, W. Gieskes, W. Klassen, and H. de Baar (2003), The contribution of ocean-leaving DMS to the global atmospheric burdens of DMS, MSA, $\mathrm{SO}_{2}$ and NSS $\mathrm{SO}_{4}=$, Global Biogeochem. Cycles, 17(2), 1056, doi:10.1029/ 2002 GB001937.

Hinds, W. C. (1999), Aerosol Technology: Properties, Behavior, and Measurement of Airborne Particles, John Wiley, New York.

Hochella, M. F., Jr., S. K. Lower, P. A. Maurice, R. L. Penn, N. Sahai, D. L. Sparks, and B. S. Twinning (2008), Nanominerals, mineral nanoparticles, and Earth systems, Science, 319, 1631-1635, doi:10.1126/science.1141134.
Jeong, G. Y. (2008), Bulk and single-particle mineralogy of Asian dust and a comparison with its source soils, J. Geophys. Res., 113, D02208, doi:10.1029/2007JD008606.

Jickells, T. D., et al. (2005), Global iron connections between desert dust, ocean biogeochemistry, and climate, Science, 308, 67-71, doi:10.1126/science.1105959.

Kandler, K., N. Benker, U. Bundke, E. Cuevas, M. Ebert, P. Knippertz, S. Rodríguez, L. Schütz, and S. Weinbruch (2007), Chemical composition and complex refractive index of Saharan Mineral Dust at Izaña, Tenerife (Spain) derived by electron microscopy, Atmos. Environ., 41, 8058-8074, doi:10.1016/j.atmosenv.2007.06.047.

Kandler, K., et al. (2009), Size distribution, mass concentration, chemical and mineralogical composition and derived optical parameters of the boundary layer aerosol at Tinfou, Morocco, during SAMUM 2006, Tellus, Ser. B, 61, 32-50, doi: $10.1111 /$ j.1600-0889.2008.00385.x.

Klose, M., and Y. Shao (2012), Stochastic parameterization of dust emission and application to convective atmospheric conditions, Atmos. Chem. Phys., 12, 7309-7320.

Kok, J. F., E. J. R. Parteli, T. I. Michaels, and D. Bou Karam (2012), The physics of wind-blown sand and dust, Rep. Prog. Phys., 75, 106901, doi:10.1088/0034-4885/75/10/106901.

Mahowald, N. M., et al. (2009), Atmospheric iron deposition: Global distribution, variability, and human perturbations, Annu. Rev. Mar. Sci., 1, 245-278, doi:10.1146/annurev.marine. 010908.163727.

Mason, J. A., R. S. B. Greene, and R. M. Joeckel (2011), Laser diffraction analysis of the disintegration of aeolian sedimentary aggregates in water, Catena, 87, 107-118.

Pell, S. D., and A. R. Chivas (1995), Surface features of sand grains from the Australian continental dunefield, Palaeogeogr. Palaeoclimatol. Palaeoecol., 113, 119-132.

Radhi, M., M. A. Box, G. P. Box, R. M. Mitchell, D. D. Cohen, E. Stelcer, and M. D. Keywood (2010a), Size-resolved mass and chemical properties of dust aerosols from Australia's Lake Eyre Basin, Atmos. Environ., 44, 3519-3528, doi:10.1016/j.atmosenv.2010.06.016.

Radhi, M., M. A. Box, G. P. Box, R. M. Mitchell, D. D. Cohen, E. Stelcer, and M. D. Keywood (2010b), Optical, physical and chemical characteristics of Australian continental aerosols: Results from a field experiment, Atmos. Chem. Phys., 10, 5925-5942, doi:10.5194/acp-10-5925-2010.

Raiswell, R., and D. E. Canfield (2012), The iron biogeochemical cycle past and present, Geochem. Perspect., 1, 1-220, doi: $10.7185 /$ geochempersp.1.1.

Scheuvens, D., K. Kandler, M. Küpper, K. Lieke, S. Zorn, M. Ebert, L. Schütz, and S. Weinbruch (2011), Individual-particle analysis of airborne dust samples collected over Morocco in 2006 during SAMUM 1, Tellus, Ser. B, 63, 512-530, doi: 10.1111/j.1600-0889.2011.00554.x.

Shao, Y., K. H. Wyrwoll, A. Chappell, J. Huang, Z. Lin, G. H. McTainsh, M. Mikami, T. Y. Tanaka, X. Wang, and S. Yoon (2011), Dust cycle: An emerging core theme in Earth system science, Aeolian Res., 2, 181-204, doi:10.1016/j.aeolia. 2011.02.001.

Shi, Z., L. Shao, T. P. Jones, and S. J. Lu (2005), Microscopy and mineralogy of airborne particles collected during severe dust storm episodes in Beijing, China, J. Geophys. Res., 110, D01303, doi:10.1029/2004JD005073.

Shi, Z., M. D. Krom, S. Bonneville, A. R. Baker, T. D. Jickells, and L. G. Benning (2009), Formation of iron nanoparticles and increase in iron reactivity in the mineral dust during simulated cloud processing, Environ. Sci. Technol., 43, 6592-6596, doi:10.1021/es901294g. 
Shi, Z., M. D. Krom, T. D. Jickells, S. Bonneville, K. S. Carslaw, N. Mihalopoulos, A. R. Baker, and L. G. Benning (2012), Impacts on iron solubility in the mineral dust by processes in the source region and the atmosphere: A review, $\mathrm{Ae}$ olian Res., 5, 21-42, doi:10.1016/j.aeolia.2012.03.001.

Sokolik, I. N., and O. B. Toon (1999), Incorporation of mineralogical composition into models of the radiative properties of mineral aerosol from UV to IR wavelengths, J. Geophys. Res., 104, 9423-9444.

Usher, C. R., A. E. Michel, and V. H. Grassian (2003), Reactions on mineral dust, Chem. Rev., 103, 4883-4940, doi:10.1021/cr020657y.
Walker, T. R. (1979), Red colour in eolian sand, in A Study of Global Sand Seas, edited by E. D. McKee, U.S. Geol. Surv. Prof. Pap., 1052, 62-81.

Wasson, R. J. (1983), Dune sediment types, sand colour, sediment provenance and hydrology in the Strzelecki-Simpson dunefield, Australia, in Eolian Sediments and Processes, edited by M. E. Brookfield and T. S. Ahlbrandt, pp. 165195, Elsevier, Amsterdam.

Wright, J., B. J. Smith, and W. B. Whalley (1998), Mechanisms of loess-sized quartz silt production and their relative effectiveness: Laboratory simulations, Geomorphology, 23, 15-34, doi:10.1016/S0169-555X(97)00084-6. 